\title{
Lengthening Biolubricants' Lifetime by Using Porous Materials
}

\author{
Estibaliz Aranzabe, Arrate Marcaide, \\ Marta Hernaiz and Nerea Uranga \\ Fundacion TEKNIKER \\ Spain
}

\section{Introduction}

The most of the lubricants such as automotive lubricants, gear oils, automatic transmissions fluids, engine lubricants, compressors oils... have being disposed on the environment for years, without any special care. Waste disposal is becoming a major source of concern and the tolerance of unnecessary pollution by society decreases 1 .

As it has been described in the European General Instructions, 75/439/CEE, 78/319/CEE and $87 / 101 / C E E$, used lubricants as toxic disposals are attached to several rules and standards. One of the main problems of lubricants is the proportion of them lost into the environment in the course of routine usage ${ }^{2}$. The spillage of lubricants to the environment is one of the main problems during their routine usage. About 600000 Tonnes of lubricating oils per year are lost without control which implies a hard damage to the environment because just 1 litre of lubricant over the water is needed to form a film of oil of $4000 \mathrm{~m}^{2}$.

In Europe the $50 \%$ of the lubricants are consumed for automotive purposes, and $35 \%$ for general industries (compressors, turbines, hydraulics, bearing, metal-working). More than $95 \%$ of the market is dominated by the mineral oil based lubricants which are polluting the environment but have in this moment a lower price and high availability. The market of biolubricants is still in a development stage and there is a priority to formulate high performance biodegradable lubricants.

The growing importance of environmental awareness and regulations has leaded to new demands of lubricants based on biodegradable materials. Several national ecolabels/schemes and one international standard have been developed in the recent years setting requirements for the ecological and technical characteristics of lubricants: The main difference relating to the ecological criteria for lubricants is the use of renewable raw materials, a newly included concept that aids to meet the three pillars of sustainability. An example of requirements concerning renewable raw material are the Swedish Standard for greases (SS 155470 Greases) and the Nordic Swan for lubricating oils.

\footnotetext{
1 "Product Reviews: Liquid waste disposal and Recovery - Lubricant Recycling", Ind. Lub. Trib., 1994, $46,(4), 18-26$.

2 "The Need For Biodegradable Lubricants", Ind. Lubr. and Trib., 1992, 44, (4), 6-7.
} 
The final criteria of European Eco-label ${ }^{3}$ for lubricants was published in the Official Journal of 5 May 2005 and it will be valid until June 2011. It comprises hydraulic oils, greases, chainsaw oils, two stroke oils, concrete release agents and other total loss lubricants, for use by consumers and professional users. The ecological criteria for the product group "lubricants" shall be valid for 4 years from the date of notification of the Decision. On the occasion of the next revision particular attention will be paid to following issues: the possibility of including an additional test for toxicity to flora, the use of standardised performance tests, evaluating the criterion on biodegradability and bio-accumulative potential, the percentage\&sourcing of the renewable raw materials, static or dynamic link to the OSPAR list and the Community list of priority substances in the field of the water policy, possible extension of the scope of the group, evaluating whether criteria need to be more ambitious, evaluating the consumer information.

The criteria are designed to reflect the philosophy of the new EU regulatory framework for chemicals (REACH - Registration, Evaluation and Authorization of Chemicals) ${ }^{4}$ and are in line with the Dangerous Substances Directive and Dangerous Preparations Directive. Besides that, substances appearing in the Community list of priority substances in the field of water policy and the OSPAR List of Chemicals for Priority Action, shall not be intentionally added as an ingredient in a product eligible for the European eco-label.

According to the background document for the European Eco-label to lubricants, Several European countries regulations and policies exist in favour of biolubricants. In Germany, Austria and Switzerland is forbidden the use of mineral oil based lubricants around inland waterways and in forest areas. In Italy there is a tax for mineral oils. In Portugal there is a regulation that mandates the use of biolubricant two-stroke engine oils in outboard boat engines. In Belgium is required to use a biolubricant in all operations taking place near nonnavigable waters. In the Netherlands there is an action programme in favour of biolubricants since 1996 .

The use of non-toxic lubricant will improve health and safety of all individuals that are in contact with products and materials during their whole lifecycle. At the end of the life of the lubricants, recycling or disposal will release lubricants to the environment and again to individuals, either directly or via intermediate steps such as animal food or drinking water. Such a release of solid and/or liquid wastes can affect for many years the quality of life. For instance, the very harmful PCB's have been already been banned 20 years ago. Notwithstanding that, they are still being released by dismantling of old electrical transformers containing these products as coolants.

The use of biodegradable lubricants will reduce problems on disposal. In most of the countries in the European Union each consumer is responsible of its own lubricant. It means that disposal of lubricants must be done by each consumer following the rules of each country. The non fulfillment of these rules can be fined or even imprisoned. Then, mineral oil based lubricants can be critical when arrive to the environment (earth and water). They contain substance which are not compatible with the biosphere and can cause damage to soil organisms, plants, aquatic organism. The use of biodegradable lubricant means that in 28 days, the $98 \%$ of the lubricant will be biodegradable and no film of oil will remain on the

\footnotetext{
3 "Ecological Criteria for the award of the Community ecolabel to lubricants"- Regulatory Committee of the European Parliament and of the Council- 2005.

${ }^{4}$ Regulation of the European Parliament and of the council concerning the Registration, Evaluation, Authorisation and Restrictions of Chemicals.
} 
water. The soft impact produced to the environment by biodegradable lubricants spill incidents due to their non toxic formulation makes it less worrying and preserves the environment from an irreversible deterioration. Try to restore the nature as well as difficult (sometimes impossible) is very expensive. Clearly, disposing of non-toxic and biodegradable lubricant will protect consumers.

Today, to deserve the name of "environmental friendly", a lubricant must possess several characteristics in different aspects as biodegradability, toxicity, emissions and efficiency. Vegetable oils, carefully selected esters and polyglycolethers form the bulk of base fluids in this type of product, generally given the generic name of biodegradable lubricants $5,6,7$.

Esters in general are known as good lubricants 8 , with low volatility, low pour points $\left(-65^{\circ} \mathrm{C}\right.$ compared with $-15{ }^{\circ} \mathrm{C}$ for mineral oils), good solubility for additives and high viscosity indexes. There are several types of biodegradable esters: dibasic esters or diesters, polyol esters (hindered esters), and phosphate esters. They find applications in engines, gears and compressors where cleanliness is important and the latter type as a fire-resistant fluid. Moderate corrosion behaviour is the major drawback. It is recommended to use saturated natural esters (low iodine value) to formulate biodegradable oils, because they have better thermal and oxidation stability.

Lubricants based on vegetable oils still comprise a narrow segment; however, they are finding their way into such applications as chainsaw bar lubricants, drilling muds and oils, straight metalworking fluids, food industry lubricants, open gear oils, biodegradable grease, hydraulic fluids, marine oils and outboard engine lubricants, oils for water and underground pumps, rail flange lubricants, shock absorber lubricants, tractor oils, agricultural equipment lubricants, elevator oils, mould release oils, two stroke engine lubricants and other. Volatility or viscosity index being cited the most often, vegetable oils clearly outperform mineral oils. Many of the other properties are similar between the fluids or may be manipulated with additives. However, low resistance to oxidative degradation and poor low temperature properties are major issues for vegetable oils.

The lubricant industry's inability to overcome these limitations ignited a rapid rise in demand of highly biodegradable synthetic basestocks as low molecular weight poly aolefins (PAO 2 or PAO 4, essentially 20:1 and 10:1 mixtures of hydrogenated dimers:trimers of alpha-decene), di alkyl adipates (iso decyl, iso tridecyl) or polyol esters (mostly neopentyl glycol or trimethylol propane with fatty acids). The synthetic basestocks also have some imperfections, such as higher volatility of PAOs, seal swelling of adipates, questionable biodegradability of some polyols, and, frequently the major issue, costs of nearly three times higher than that of vegetable oils9.

Polyalphaolefin fluids are enjoying a growing market share as synthetic base stocks. They are manufactured by the oligomerization of 1-decene, followed by hydrogenation and distillation into different viscosity grades. Applications range from hydraulic fluids to car

\footnotetext{
${ }^{5}$ Carnes K. "University Tests Biodegradable Soy-Based Railroad Lubricant", Hart's Lubricantes world 1998, Vol. September, pp 45-47.

${ }^{6}$ Glancey J.L., Knowlton S., Benson E.R. “Development of a High-Oleic Soybean Oil-based Hydraulic Fluid", Lubricants World 1999, Vol. January, pp 49-51.

7 Rajewski T.E., Fokens J.S., Watson M.C., "The development and Application of Syntetic Food Grade Lubricants", Tribology, 2000, Vol 1, pp 83-89.

${ }^{8}$ W. J. Bartz: “Comparison of Synthetic Fluids", Lub. Eng., 1992, 48, (10), 765-774.

9 S.Z.Erhan: "Lubricant basestocks from vegetable oils", Industrial Crops and Products 11 (2000) 277282
} 
motor oils10,11,12.They have excellent thermal, oxidative and hydrolytic stabilities. Recently, it has been reported that $2 \mathrm{cSt}$ and $4 \mathrm{cSt}$ PAO fluids are easily biodegradable, so they can be used in environmentally sensitive applications ${ }^{13}$.

From the Polyglycol side only Polyethyleneglycols (PEG) with mol-weights lower than 2000 are relatively good biodegradable, but water-soluble, means they migrate into the soil after an oil accident or via leakages. Polypropylenes (PPG) are not water-soluble but not easily biodegradable substance. Furthermore PAG's are only partly or even not miscible with esters, mineral oils, etc. But the compatibility of all the fluids is an absolutely neccesary item in case of re-filling or replacement of mineral oil by biodegradable fluids. The polyglycol used in this study (of about $320 \mathrm{cSt}$ of viscosity at $40^{\circ} \mathrm{C}$ ) is not biodegradable.

There is still a priority to formulate high performance biodegradable lubricants. The main limitation to introduce bio-degradable lubricants is the lack of knowledge of the performance of the biolubricants. A review of the state of the art has been developed to check the status of condition monitoring in mineral and biodegradable oils and greases $14,15,16$. Results indicated that there is hardly any documentation (application note, technical papers, standards) concerning how to tackle bio-lubricants. Also, documentation concerning how to perform a condition monitoring of greases is hardly non-existant. The procedures and test methods to detect contaminants has been developed for mineral based lubricants, but new procedures has to be developed for environmentally friendly lubricants. In order to assess this performance, it is important to understand how degradation processes occurs at biodegradable fluids $17,18,19$ and identify adequate control parameters, limits and sampling frequency (or re-greasing frequency). Apart from hydraulic fluids 20 , there is no information about how to efficiently handle the monitoring of biodegradable lubricants.

Table 1.1shows the status in the definition of parameters, limits and sample frequencies at different lubricant types (lubricating oils and greases and biodegradable lubricating oils and greases). The OK sign $(\sqrt{ })$ indicates that the field (parameters, limits and sample frequencies)

${ }_{10}$ C-X. Xiong: "The structure and Activity of Polyalphaolefins as Pour-Point Depressants", Lub. Eng., 1993, $\underline{49},(3), 196-200$.

${ }^{11}$ G Kumar: "New Polyalphaolefin Fluids for specialty applications", Lub. Eng., 1993, 49, (x), 723-725.

12 R. L. Shubkin: "Polyalphaolefins: Meeting the Challenge for High-Performance Lubrication", Lub. Eng., 1994, 50, (x), 196-201.

${ }^{13}$ J. F. Carpenter: "Biodegradability of Polyalphaolefin (PAO) Basestocks", Lub. Eng., 1994, 50, (5), 359362.

${ }^{14}$ M.K. Williamson "The emerging Role of Oil analysis in Enterprise-Wide decision making". Practicig Oil analysis 2000. pp. 187-200.

15 “Lubricants and lubrication". T. Mang, W. Dresel (Eds). Wiley-VCH. 2001

16 "Lubricating grease guide". Fourth Edition. National Lubricating Grease Institute (NLGI)

17 A. Adhvaryu, "Oxidation kinetics studies of oils derived from unmodified and genetically modified vegetables using pressurized differential scanning calorimetry and nuclear magnetic resonance spectroscopy". Thermochimica Acta, 364, 87-97. 2000

18 N.J. Fox, A.K. Simpson, G.W. Stachowiak, "Sealed Capsule Differential Scanning Calorimetry-An Effective Method for Screening the oxidation Stability of vegetable oil formulations". Lubrication Engineering, 57, 14-20. 2001

19 A. Adhvaryu, "Tribological studies of thermally and Chemically modified vegetable oils use as environmentally friendly lubricants". Wear, 257, 359-367, 2004

${ }^{20}$ F.Novotny-Farkas, P. Kotal, W. Bohme. "Condition monitoring of biodegradable lubricants". World Tribology Congress. Vienna. 2001 
has already been properly defined and all aspects of these fields have been put into practice. The OK sign and plus mark $(\sqrt{ } /+)$ indicates that some studies have been carried out, however a improvement of the definition is necessary. The plus sign (+) indicates the field that we are trying to improve by means of this study. A high advance has been obtained in the work of obtaining a proper definition of each of fields. The question mark (?) indicates that there is not any adequate definition of the field and it is not going to obtain by means of this study.

\begin{tabular}{|c|c|c|c|c|}
\hline & $\begin{array}{c}\text { Lubricating } \\
\text { oil }\end{array}$ & $\begin{array}{c}\text { Biodegradable } \\
\text { Lubricating Oil }\end{array}$ & $\begin{array}{c}\text { Lubricating } \\
\text { Grease }\end{array}$ & $\begin{array}{c}\text { Biodegradable } \\
\text { Lubricating } \\
\text { Grease }\end{array}$ \\
\hline Parameters & $\checkmark$ & $\checkmark$ & $\checkmark /+$ & + \\
\hline Limits & $\checkmark$ & + & $\checkmark /+$ & + \\
\hline $\begin{array}{c}\text { Sample } \\
\text { frequencies }\end{array}$ & $\checkmark$ & + & $?$ & $?$ \\
\hline
\end{tabular}

Table 1. Knowledge of parameters that have to be measured, limits and sample frequencies at lubricating oils, biodegradable lubricating oils, lubricating greases and biodegradable lubricating greases.

The development of the technology on different areas such as manufacturing, electronic and nanotechnology has allow us to develop new devices for improving the lubricants control and has opened an wide range of research areas. The main objectives of these developments are the following: to avoid the lubricant degradation by means of the use of filters or additives and to control "on-line" the condition of the lubricant by means of sensors 21,22 .

This chapter includes a first proposal for the condition monitoring strategy developments of biolubricants (BIOMON Project contract $\mathrm{N}^{\circ} \mathrm{COOP}-\mathrm{CT}-2004-508208$ ) and some results concerning the potential of porous materials for trapping oxidation molecules of the biolubricants during use for lengthening their lifetime instead of traditional antioxidant additives (SOILCYProject contract N515848).

\section{Degradation mechanism of biolubricants and analytical techniques used for biolubricants monitoring}

A commercial hydraulic fluid (ISO VG 68/MP=Multi-purpose) which is currently in use for roller bearing purposes has been used in this study as fully formulated mineral oil. EP additives but no antioxidants have been included in its formulation. Secondly, a biodegradable nearly fully saturated ester has been developed in order to study its oxidation process. EP \& antioxidant additives have been included in the formulation of the biodegradable oil.

\footnotetext{
${ }^{21}$ Arnaiz, A., Aranzabe, A., Terradillos, J., Merino, S., Aramburu, I.: New micro-sensor systems to monitor on-line oil degradation, Comadem 2004. pp. 466-475

${ }^{22}$ Kristiansen, P., Leeker, R.: U.S.Navy's in-line oil analysis program, , lubr. Fluid powerj. 3, 3-12, aug 2001.
} 


\subsection{Degradation mechanism}

One of the important modes of lubricant degradation is oxidation. Oxidation products are the primary cause of metal corrosion, viscosity increase and sludge and varnish formation in lubrication systems. It is well-known that a lubricant when exposed to air at high temperatures undergoes a series of chain reactions that form peroxides, which upon further reaction produce low molecular weight products (products of the same or lower molecular weight than the original oil). The LMW products are a mixture of ketones, aldehydes, alcohols and acids. These primary oxidation products can polymerize to form higher molecular weight (HMW) viscous liquids, sludge and varnish.

Some studies of the oxidation mechanism of the vegetable oils reveal that the oxidation mechanism may be presented as a free radical chain reaction. It consists of four distinct reaction steps: initiation, propagation, branching and ending. These steps have been analyzed.

The initiation step consists of forming free radical derived from $\mathrm{R}$ substance that undertake the peroxidation and it takes place due the high transformation energy, UV light of the mechanical shear stresses applied to a molecule. The appearance of the free radicals is due to one or more external factors (high temperature, moisture, pressure, oxygen presence) or internal factors (easily oxidable impurities, for instance: aromatic diphenol compounds). Under certain conditions the external factors produce the $\mathrm{O}_{2}$ activation and the development of some reactive elements and radicals. Although the radicals of the oxygen may accidentally appear, the reactions that release them are enough to initiate the formation of some free radicals from the initial organic substances.

The propagation step consists in the continuation of forming free radicals especially of the derived peroxides from the substance that bear the oxidation progress. The first propagation step involves an alkyl radical reacting with oxygen to form an alkyl peroxy radical (ROO). The second propagation step is the hydrogen abstraction from a hydrocarbon molecule by an alkyl peroxy-radical to form a hydroperoxide and another alkyl radical.Generally the alkyl peroxy radicals are in a greater concentration than the alkyl radicals. This is due to the combination between high oxygen concentration with alkyl radical rather than the slow reaction rate of alkyl peroxy radical with hydrocarbon.

The chain branching steps begin with the decomposition of hydroperoxide ( $\mathrm{ROOH})$ in alkoxy radicals and hydroxy radical. This reaction has a great activation energy and the alkoxy and hydroxy radicals can react on with hydrocarbons to form more alkyl radicals, alcohols and water. Secondary and tertiary alkoxy radicals, will form aldehydes and ketones respectively. These condense via acid catalysed aldol reactions can lead to polymeric degradated products.

The ending step may take place by the combination of the alkyl radicals. Two alkyl radicals can combine to form a hydrocarbon molecule. Alternatively, an alkyl radical may combine with an alkyl peroxy radical (ROO.) to form a peroxide or two alkyl peroxy radicals (2ROO.) (ROOR.).

\subsection{Oxidation tests}

Oxidation tests can be differentiated into two groups: one kind of tests describe the condition of the lubricant after a defined test period by measuring several aging indicating parameters like acid number, viscosity change and sludge formation. The 1000-h TOST according to DIN 51587 and IP 280 oxidation test are examples for that kind of tests. Another group of oxidation tests measure the so-called induction time (time from the 
beginning of the oxidation to the autocatalytic phase of the autoxidation) by recording constantly or after defined periods of time the aging indicating parameters. Typical examples of this group are the lifetime TOST test according to ASTM-D 943 or the rotary bomb test (ASTM-D 2272) where the drop of oxygen pressure indicates the aging of the lubricant. More recently the high pressure differential scanning Calorimetry (HPDSC) as well as the sealed capsule differential scanning calorimetry (SCDSC) has been applied more and more to measure the stability of different antioxidants and formulations.

These tests for lubricants are a function of temperature or other parameters. These aging tests are carried out on base oils as well as fully formulated products to test the efficiency of additives. There is a big variety of standardized test methods where we have duration of test between hours and months. The majority of these tests is based on exposing the test fluids to oxygen or air at relatively high temperatures in presence of catalyst metals to increase oxidation rates and to reduce the testing period. Oxidation stability is assessed by quantitative determination of oxidation products, oxygen absorption, viscosity changes, change in acidity or formation of sludge.

The TOST (turbine oxidation stability test) is used to evaluate the oxidation stability of inhibited steam turbine oils in presence of oxygen, water, copper and iron catalyst at $95^{\circ} \mathrm{C}$. The test is continued until the total acid number (TAN) measured reaches at least $2.0 \mathrm{mg} / \mathrm{g}$ $\mathrm{KOH}$. The number of test hours required for the oil to reach $2.0 \mathrm{mg} / \mathrm{g} \mathrm{KOH}$ is the "oxidation lifetime" of an oil.

The oxidation stability by rotary bomb test (ASTM D 2272) oxidizes the oil at $150^{\circ} \mathrm{C}$ in presence of water, metallic copper catalyst and oxygen at $620 \mathrm{kPa}$ pressure. The time is registered to reach a specific pressure drop and this is an indication of the oxidation stability.

The aging test according to Baader (DIN 51554) is an oxidation test of atmospheric air and intermittent immersion of a copper spiral at a test temperature of $95^{\circ} \mathrm{C}$. After a given time, the saponification number in $\mathrm{mg} / \mathrm{g} \mathrm{KOH}$ is measured.

For the oxidation stability of lubricating greases by oxygen bomb method grease is oxidized in a bomb heated to $99^{\circ} \mathrm{C}$ and filled with oxygen at 110 psig. After a defined time, the drop of pressure is recorded. The degree of oxidation after a given period of time is determined by the corresponding decrease of oxygen pressure.

In the table below equivalent standards are grouped together which are identical or technically equivalent respectively 23 .

New biodegradable polyol ester base stocks formulated with the appropriate ashless additive technology outperform vegetable oils both hydrolytically and oxidatively and modified versions of the ASTM D 943 and D2274 tests, in which no water is employed have shown that they are very suitable for the evaluation of the long-term oxidative stability of biodegradable polyol esters 24 .

Tekniker proposes the development of a new oxidation procedure for biodegradable lubricants because this kind of oils needs higher temperatures for degradation. Based on Tekniker experience, it is proposed a new oxidation test running in a bath reactor (figure 1) at $120^{\circ} \mathrm{C}$ with stirring, air flux and without presence of water and catalyst.

\footnotetext{
${ }^{23}$ Mang, T. y Dresel, W. (eds.), Lubricants and Lubrication, $2^{\mathrm{a}}$ edición, Wiley-VCH, Weinheim (2007).

${ }^{24}$ C.Duncan (2002), Lubrication Engineering, "Ashless Additives and New Polyol Ester Base Oils Formulated for Use in Biodegradable Hydraulic Fluid Applications"
} 


\begin{tabular}{|c|c|c|c|c|l|}
\hline AFNOR & ASTM & DIN & IP & ISO & \multicolumn{1}{|c|}{ Test method } \\
\hline & & $51352 \mathrm{t} 1$ & 48 & & $\begin{array}{l}\text { Determination of oxidation } \\
\text { characteristics of lubricating oil }\end{array}$ \\
\hline T60-150 & D943 & 51587 & & 4263 & $\begin{array}{l}\text { Determination of oxidation } \\
\text { characteristics of lubricating oil acc.to } \\
\text { Baader }\end{array}$ \\
\hline & D2893 & 51586 & $\begin{array}{l}\text { Determination of oxidation stability } \\
\text { of inhibited mineral oils }\end{array}$ \\
\hline & D4742 & Determination of oxidation stability \\
\hline & D2274 & & $\begin{array}{l}\text { Determination of oxidation } \\
\text { characteristics of extreme-pressure } \\
\text { lubricating oils }\end{array}$ \\
\hline & D942 & 51808 & 142 & $\begin{array}{l}\text { Oxidation stability of gasoline engine } \\
\text { oils by thin film oxygen uptake } \\
\text { (TFOUT) }\end{array}$ \\
\hline
\end{tabular}

Table 2. Equivalent oxidation standards

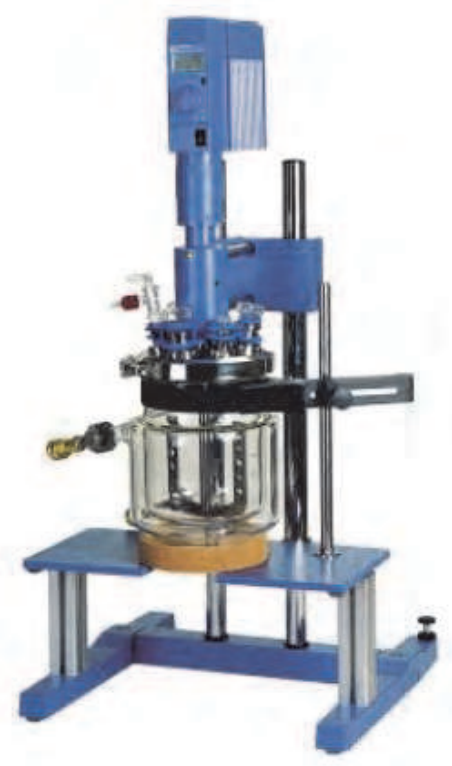

Fig. 1. Oxidation reactor 
The table 3 shows the advantages of the oxidation procedure proposed for biolubricants compared with the oxidation standard procedure for mineral lubricants.

\begin{tabular}{|l|l|}
\hline $\begin{array}{l}\text { Heterogeneous samples are taken due to the } \\
\text { absence of stirring }\end{array}$ & $\begin{array}{l}\text { Homogeneous samples are taken due to the } \\
\text { presence of stirring }\end{array}$ \\
\hline $\begin{array}{l}\text { Long degradation time due to the } \\
\text { temperature of the test. }\end{array}$ & $\begin{array}{l}\text { Shorter degradation time due to the } \\
\text { temperature of the test }\end{array}$ \\
\hline $\begin{array}{l}\text { Heterogeneous samples are taken due to the } \\
\text { absence of stirring }\end{array}$ & $\begin{array}{l}\text { Homogeneous samples are taken due to the } \\
\text { presence of stirring }\end{array}$ \\
\hline
\end{tabular}

Table 3. Oxidation standards

\subsection{Analytical techniques used for biolubricants monitoring}

Oxidation is a major source for viscosity increase, acid number increase or corrosion, additive depletions, dispersant failures, base oil deterioration, varnish and sludge formation, filter plugging, oil darkening, as well as many of the wear root causes. For this reason, there have been many analytical techniques to evaluate the oxidation state of the lubricant.

The table 4 shows the chemical, tribological and environmental analysis selected for monitoring biolubricants.

The chemical analysis includes the following parameters: Acid Number (ASTM D 974-04), Viscosity at $40^{\circ} \mathrm{C}$ (ASTM D 445), Density (PE-5053-AI), Emulsification Capacity (ASTM D 1401), DSC (PE-5035-AI), Fourier Transform Infrared Spectroscopy (FTIR) (PE-5008-AI), Remaining Useful Life Number (RULER) (PE-TA.090) and \%Solids. Sliding tests has been selected in the tribological field. Finally, in accordance with the European Ecolabel for lubricants, the following environmental analyses have been selected: Ready Biodegradability according to OECD 301F Test, Inherent Biodegradability according to OECD 302B Test and Toxicity according to OECD 202 Test.

\begin{tabular}{|l|l|}
\hline \multicolumn{1}{|c|}{ Analytical parameter } & \multicolumn{1}{c|}{ Test } \\
\hline Acid Number & ASTM D 974-04 \\
\hline Viscosity at $40^{\circ} \mathrm{C}$ & ASTM D 445 \\
\hline Density & PE-5053-AI \\
\hline Emulsification capacity & ASTM D 1401 \\
\hline Differential Scanning Calorimetry & PE-5035-AI \\
\hline $\begin{array}{l}\text { Fourier Transform Infrared } \\
\text { Spectroscopy }\end{array}$ & PE-5008-AI \\
\hline Remaining Useful Life & PE-TA.090 \\
\hline $\begin{array}{l}\text { Sliding tests } \\
\text { Ready and Inherent Biodegradability }\end{array}$ & DIN 51834-2 \\
\hline OECD 301F, \\
Toxicity (algae, daphnia) & OECD 201, 202 \\
\hline
\end{tabular}

Table 4. Analytical techniques for biolubricants monitoring 


\subsubsection{Chemical analysis}

\subsubsection{Acid number (ASTM D974-04)}

Both in new lubricants and in-service lubricants, acidic constituents will appear, either in the form of additives or as a result of the oxidation of lubricant. The Acid Number test method is a measurement of the quantity of those acidic constituents. Measurement has been by titration which estimates the amount of $\mathrm{KOH}$ which is necessary to neutralize the acid compounds of the oil).

\subsubsection{Viscosity at $40^{\circ} \mathrm{C}$ (ASTM D445)}

The viscosity remains the most important property of the oil as part of the oil condition monitoring. Viscosity measurements have been done following ASTM D 445 standard. In general, the variation of oil viscosity can be caused by:

- The increase of viscosity results from the oxidation and/or polymerization of the oil, evaporation of the most light fractions even water presence or insoluble oxides formation.

- The decrease of viscosity may be due to thermal cracking of the molecules of the lubricant, or shear stress from the viscosity modifiers....

\subsubsection{Density (PE-5053-AI)}

Density is the mass of a unit volume of a substance. Its numerical value varies with the units used. A high level of oxidation and/or polymerization of the oil, causes an increase in density values.

\subsubsection{Emulsification capacity (ASTM D1401)}

This test method measures the ability of petroleum oils or synthetic fluids to separate from water. This test provides a guide for determining the water separation characteristics of oils subject to water contamination and turbulence. It is used for specification of new oils and monitoring of in-service oils.

\subsubsection{Differential scanning calorimetry (PE-5035-AI)}

Samples are tested at extreme conditions of temperature, pressure and in an oxidative environment. Remaining useful life can be determined concerning the oxidative stability. At constant temperature, the lubricant degradation takes place at a time called "onset time", with its corresponding heat exchange. This value can give an idea of the oil stability.

\subsubsection{Fourier transform infrared spectroscopy (PE-5008-AI)}

The IR Spectroscopy is a well known technique for analysing the chemical properties of the oil such as oxidation products or additives.

\subsubsection{Remaining useful life. RULER. (PE-TA.90)}

The RULER (Remaining Useful Life) is a useful parameter to control the antioxidants consumption in biodegradable oils.

The voltammetric test results are based on current, voltage and time relationships at the 3electrode sensing system with a small, easily polarized microelectrode, and a large nonpolarizable reference electrode. In performing a voltammetric analysis, the potential across the electrodes varies linearly with time (from 0 to $1.7 \mathrm{~V}$ at a rate of $0.1 \mathrm{~V} /$ second), and the resulting current is recorded as a function of the potential. With increased voltage to the sample in the cell, the various dissolved antioxidants oxidize electrochemically resulting in an oxidation reaction that can be used to predict the remaining useful life of the oil. 


\subsubsection{Tribological analysis}

\subsubsection{Sliding tests (DIN 51834-2)}

With the SRV tribometer reciprocating sliding tests in standard conditions using AISI 52100 steel standard balls and discs can be useful for finding any difference in the behavior of new and aged oils based on the results of friction (COF) and wear obtained during the tribological tests.

\subsubsection{Environmental analysis}

\subsubsection{Ready biodegradability (OECD 301F)}

If a chemical gives positive in this test will undergo rapid an ultimate biodegradation $\left(\mathrm{CO}_{2}+\mathrm{H}_{2} \mathrm{O}\right)$ in the environment and no further work on the biodegradability on the chemical, or on the possible environmental effects of biodegradation products, normally is required. Ultimate biodegradation within 28 days higher than $60 \%$ according to OECD 301 F.

\subsubsection{Toxicity algae, daphnia (OECD 201, OECD 202).}

The level al which $50 \%$ of the test organisms show an adverse (lethal) effect.

Exponentially-growing cultures of selected green algae or certain percentage of daphnia are exposed to various concentrations of the test substance under defined conditions. The inhibition of growth in relation to a control culture or the inhibition of the capability of swimming of daphnia is determined over a fixed period.

The 50\% effect level (EC50) is chosen, the level at which $50 \%$ of the test organisms show an adverse (lethal) effect.

\subsection{Identification of main condition monitoring patterns}

Regarding traditional lubricating oils, all condition monitoring parameters, limits and sample frequencies have been already established at different studies. However, there is not a clear rule of thumb, as small variations occurs in limits and sampling frequencies. Given this, the knowledge has been obtained through extensive usage occurred at WearCheck Ibérica Laboratories, which has helped to obtain enough expertise to study all condition monitoring fields.

Regarding biodegradable lubricating oil parameters that have to be measured, an extensive tribological and physico-chemical comparison has been performed between normal and biodegradable lubricants, in order to assess their conditions. The tests have demonstrated a superior working life-time for bio-degradable lubricants with respect to traditional ones that is mostly reflected in a much higher AN limit allowed for operation.

As a result, similar parameters have been defined as of primary control. However, there are two important additions. The Ruler is a parameter for on site measurement of remaining useful lifetime of the oil. The analysis performed show that rules offer a quite reliable information on usage of the oil and can complement the information indicated by AN.

Also, the \% of Solids parameter is a very useful parameter. However, it is very hard and expensive to measure and in the near future work the \% of Solids parameter have to be eliminated to the monitoring routine and must be found a new parameter cheaper and easier to use it in the monitoring routine.

Of course, these are main parameters and limits. Depending on the type of lubricant and its application and the test cost, other parameters could be useful for mineral oils monitoring, 
and biodegradable oils. For engine oils for example, it could be necessary to analyse Base Number (BN) parameter. The work should be completed with a complete identification of sample frequencies.

\begin{tabular}{|c|c|c|c|c|}
\hline & & & Monitor & Warning \\
\hline \multirow{2}{*}{ 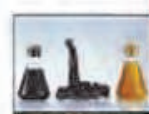 } & \multirow{2}{*}{ Degradation } & AN (mgKOH/g) & +0.5 & +1.0 \\
\hline & & Vis $40^{\circ} \mathrm{C}$ (cSt) & $\pm 15 \%$ & $\pm 20 \%$ \\
\hline & \multirow{2}{*}{ Contamination } & Water & $0.1 \%$ & $0.2 \%$ \\
\hline & & Si (ppm) & 30 & 65 \\
\hline & \multirow{2}{*}{ Wear Debris } & Fe (ppm) & 100 & 150 \\
\hline & & $\mathrm{Cu}$ (ppm) & 50 & 80 \\
\hline
\end{tabular}

\section{\begin{tabular}{|l|l|}
\hline SAMPLE FRECUENCIES & 1000 hours \\
\hline
\end{tabular}}

ANALYTICAL EQUIPMENT

\begin{tabular}{|c|c|}
\hline AN Titrometer & Viscometer \\
\hline Karl-Fischer & ICP \\
\hline
\end{tabular}

Fig. 2. Parameters, monitor and warning limits, sample frequencies and analytical equipment for mineral oils.

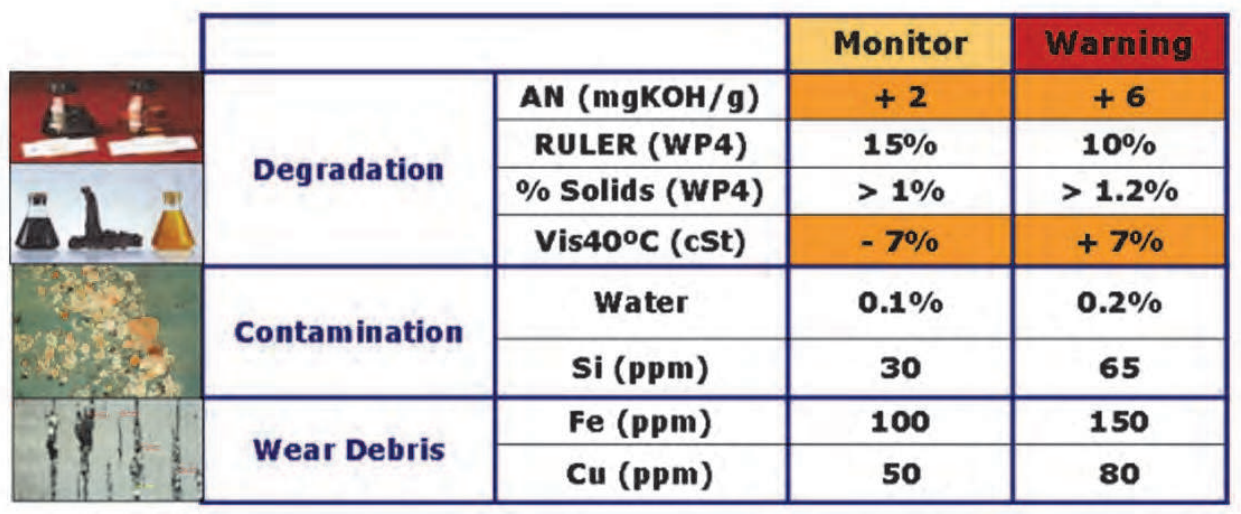

Fig. 3. Limits and parameters for biodegradable oils.

\section{New materials for enlarge biolubricants 'lifetime}

One of the main concerns of lubricants is their performance which is improved using additives. The use of additives allows increasing the performance and physical properties of oil but they also increase the cost of lubricants and may even be harmful to health or environment. 
Adsorption in a porous material of oxidation products from a biodegradable lubricant is a promising approach to improve the performance of biolubricants in an environmentally friendly way. Antioxidant additives are commonly used to improve performance of biolubricants but they are expensive and even may be harmful. The development of a sieve able to trap oxidation products may be a way to reduce or avoid the use of additives.

In our investigation, different oxidized samples of biolubricants obtained from the degradation process of TMP-trioleate have been characterized and the oxidation molecules to be trapped have been identified. The most suitable nanoporous material to trap the identified oxidation molecules has been selected. To do this the adsorption of biolubricant oxidation molecules in a nanoporous material has been examined by means of Monte Carlo (MC) and Molecular Dynamics (MD) computational methods and by means of Differential Scanning Calorimetry .

Among the different framework types BEA, MFI, LTL and FAU zeolitic structures were selected due to their suitable pore size of molecular dimensions. All of them present an extensive channel network with elliptical or circular shape and cross section ranging from 0.5 and $0.8 \mathrm{~nm}$. Besides, structural criteria, different compositions have been selected in order to analyze the effect of the physico-chemical properties of the solid surfaces (functional groups, acidity, hydrophilicity,...).

It deserves to note that from the point of view of the composition, extremely hydrophobic materials with high silica content such as Silicalite-1, or highly hydrophilic materials with relatively low silica content such as zeolite $x$, have been considered.

Prior to their use all the materials were dried and activated trough a thermal treatment using an exposure times of $2 \mathrm{~h}$ and temperatures of 150 or $300^{\circ} \mathrm{C}$. Since crystal structure and grain size and morfology influences on total porosity of the material surface area of all the samples were measured after activation with a NOVA 1200e surface area and pore size analyzer from Quantachrome Instruments. Total surface area was computed according to BET Method.

\subsection{Oxidation conditions}

In order to analyze the capacity of the selective adsorption of oxidation by-products with nanoporous materials and predict the lubricating oil oxidation state, the Differential Scanning Calorimetry (DSC) analytical technique has been used. The experimental procedure consists on an analyzed sample heating it with a programmed temperature-time sequence: $3^{\circ} \mathrm{C} / \mathrm{min}$ heating from $100^{\circ} \mathrm{C}$ at $600^{\circ} \mathrm{C}$ at 20 bar of pressure.

The oxidation method was described previously. The oxidation conditions were the following: $1.5 \mathrm{l}$ of TMP-trioleate in a bath reactor at $95^{\circ} \mathrm{C}$ with stirring, air flux and without presence of water and catalyst.

The analytical parameters monitorized were the following: Acid Number (ASTM D 974-04), DSC (PE-5035-AI), Fourier Transform Infrarred Spectroscopy (FTIR) (PE-5008-AI) and Density (PE-5053-AI). Besides that, the oxidation molecules identification at different hours of oxidation has been made by GCMS and HPLC.

After testing the capacity of different nanoporous materials, the most suitable has been tested with the TMP-trioleate at $95^{\circ} \mathrm{C}$ with stirring, air flux and without presence of water and catalyst. 


\subsection{MD simulations}

Molecular Dynamics (MD) has been used to study the interaction between the identified oxidation molecules and the selected nanoporous material. Results of the ability of the proposed material as absorbing media in terms of molecules per unit computational cell and preferred absorption sites are obtained.

The simulations were performed at established conditions of pressure a temperature using the grand canonical and the NPT ensemble. Results of the ability of the proposed material as absorbing media in terms of molecules per unit computational cell and preferred adsorption sites are obtained.

\subsection{Porous materials validation}

The hydrophilic and hydrophobic solids have showed the best performance trapping the oxidation molecules of TMP-trioleate. After testing the capacity of different nanoporous materials, the most suitable has been tested with the TMP-trioleate at $95^{\circ} \mathrm{C}$ with stirring, air flux and without presence of water and catalyst. The chemical parameter which shows the effectiveness of the tested solid is Acid Number (AN). The following figure shows the trend of this parameter during the oxidation process. As it shows, both solids hydrophilic and hydrophobic one, delay the oxidation process of the oil due, these solids trap in their pores the acid compounds generated during the oxidation.

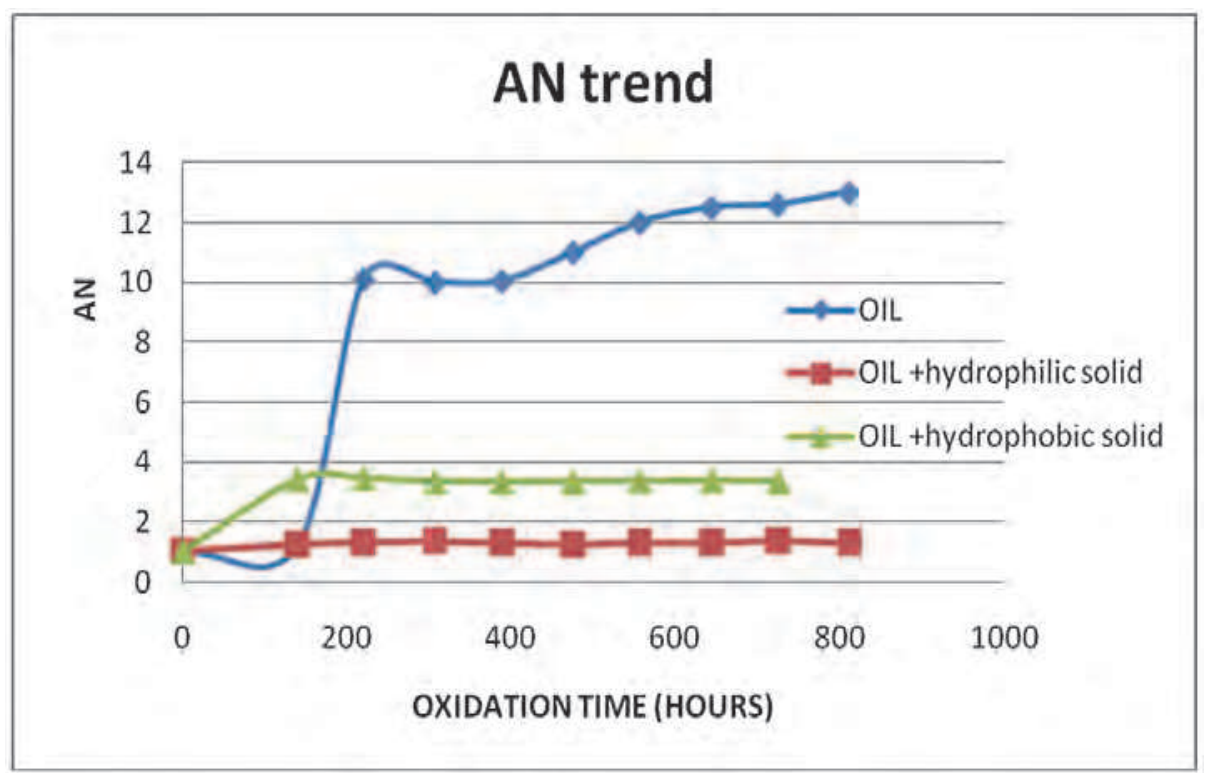

Fig. 4. AN values trend in TMP-Trioleate oxidized with and without solid.

\section{Conclusions}

In this chapter it has been exposed two main research works; the first one is a proposal for the condition monitoring strategy for biolubricants. In this sense two oils, mineral and biodegrable; have been oxidized under a new oxidation procedure, based on Tekniker 
experience, which provide more advantage than traditional tests. Thanks to the chemical, tribological and environmental analyses monitor and warning limits can be proposed for bio-oil.

As it can be sawn these limits are different as traditional limits for mineral oils, what is mean that biodegradable oils shows different oxidations trends and traditional limits used for mineral oils are nor accurate for these kind of biolubricants:

- Kinetic degradation reaction of biodegradable lubricants is differently than mineral oils and a specific maintenance approach is needed.

- DSC is a useful tool for studying the kinetic parameters of the new formulations.

- Important research must be carried out to establish warning limits for biolubricants in order to develop condition monitoring strategies, assessment in mechanical components lubricated with biodegradable fluids.

- In the standard tribological wear tests there is a direct relationship between aging hours and friction peaks. This test can be useful in the condition monitoring strategy.

The second research work exposed is the use of nanoporous materials as tramp for oxidation compounds instead to use antioxidant additives in the bio oil formulation Antioxidant additives are commonly used to improve performance of biolubricants but they are expensive and even may be harmful. The development of a sieve able to trap oxidation products may be a way to reduce or avoid the use of additives. Adsorption in a porous material of oxidation products from a biodegradable lubricant is a promising approach to improve the performance of biolubricants in an environmentally friendly way.

- The use of biodegradable lubricants will reduce problems on disposal. The biodegradability in use must be tested in these types of friendly formulations.

- The uses of hydrophilic solids delay oil oxidation, due the trap oxidation molecules.

- Acid Number (AN) seems to be a useful analytical technique for evaluate solid efficiency

\section{References}

"Product Reviews: Liquid waste disposal and Recovery - Lubricant Recycling ", Ind. Lub. Trib., 1994, 46, (4), 18-26.

“The Need For Biodegradable Lubricants", Ind. Lubr. and Trib., 1992, 44, (4), 6-7.

"Ecological Criteria for the award of the Community ecolabel to lubricants"-

Regulatory committee of the European Parliament and of the Council- 2005

Regulation of the European Parliament and of the council concerning the Registration, Evaluation, Authorisation and Restrictions of Chemicals.

Carnes K. "University Tests Biodegradable Soy-Based Railroad Lubricant", Hart's Lubricantes world 1998, Vol. September, pp 45-47.

Glancey J.L., Knowlton S., Benson E.R. “Development of a High-Oleic Soybean Oil-based Hydraulic Fluid", Lubricants World 1999, Vol. January, pp 49-51.

Rajewski T.E., Fokens J.S., Watson M.C., "The development and Application of Syntetic Food Grade Lubricants", Tribology, 2000, Vol 1, pp 83-89.

W. J. Bartz: “Comparison of Synthetic Fluids”, Lub. Eng., 1992, 48, (10), 765-774.

S.Z.Erhan: "Lubricant basestocks from vegetable oils", Industrial Crops and Products 11 (2000) 277-282 
C-X. Xiong: "The structure and Activity of Polyalphaolefins as Pour-Point Depressants", Lub. Eng., 1993, 49, (3), 196-200.

G Kumar: “New Polyalphaolefin Fluids for specialty applications”, Lub. Eng., 1993, 49, (x), 723-725.

R. L. Shubkin: "Polyalphaolefins: Meeting the Challenge for High-Performance Lubrication", Lub. Eng., 1994, 50, (x), 196-201.

J. F. Carpenter: “Biodegradability of Polyalphaolefin (PAO) Basestocks", Lub. Eng., 1994, 50, (5), 359-362.

M.K. Williamson "The emerging Role of Oil analysis in Enterprise-Wide decision making". Practicig Oil analysis 2000. pp. 187-200.

Lubricants and lubrication". T. Mang, W. Dresel (Eds). Wiley-VCH. 2001

"Lubricating grease guide". Fourth Edition. National Lubricating Grease Institute (NLGI

A. Adhvaryu, "Oxidation kinetics studies of oils derived from unmodified and genetically modified vegetables using pressurized differential scanning calorimetry and nuclear magnetic resonance spectroscopy". Thermochimica Acta, 364, 87-97. 2000

N.J. Fox, A.K. Simpson, G.W. Stachowiak, "Sealed Capsule Differential Scanning Calorimetry-An Effective Method for Screening the oxidation Stability of vegetable oil formulations". Lubrication Engineering, 57, 14-20. 2001

A. Adhvaryu, "Tribological studies of thermally and Chemically modified vegetable oils use as environmentally friendly lubricants". Wear, 257, 359-367, 2004

F.Novotny-Farkas, P. Kotal, W. Bohme. "Condition monitoring of biodegradable lubricants". World Tribology Congress. Vienna. 2001

Arnaiz, A., Aranzabe, A., Terradillos, J., Merino, S., Aramburu, I.: New micro-sensor systems to monitor on-line oil degradation, Comadem 2004. pp. 466-475

Kristiansen, P., Leeker, R.: U.S.Navy's in-line oil analysis program, , lubr. Fluid powerj. 3, 312, aug 2001.

C.Duncan (2002), Lubrication Engineering, “Ashless Additives and New Polyol Ester Base Oils Formulated for Use in Biodegradable Hydraulic Fluid Applications" 


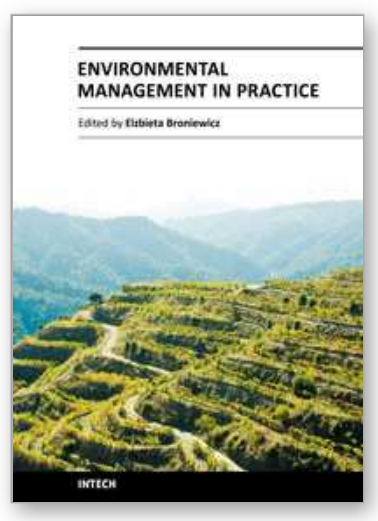

\section{Environmental Management in Practice}

Edited by Dr. Elzbieta Broniewicz

ISBN 978-953-307-358-3

Hard cover, 448 pages

Publisher InTech

Published online 21, June, 2011

Published in print edition June, 2011

In recent years the topic of environmental management has become very common. In sustainable development conditions, central and local governments much more often notice the need of acting in ways that diminish negative impact on environment. Environmental management may take place on many different levels - starting from global level, e.g. climate changes, through national and regional level (environmental policy) and ending on micro level. This publication shows many examples of environmental management. The diversity of presented aspects within environmental management and approaching the subject from the perspective of various countries contributes greatly to the development of environmental management field of research.

\section{How to reference}

In order to correctly reference this scholarly work, feel free to copy and paste the following:

Estibaliz Aranzabe, Arrate Marcaide, Marta Hernaiz and Nerea Uranga (2011). Lengthening Biolubricants' Lifetime by Using Porous Materials, Environmental Management in Practice, Dr. Elzbieta Broniewicz (Ed.), ISBN: 978-953-307-358-3, InTech, Available from: http://www.intechopen.com/books/environmentalmanagement-in-practice/lengthening-biolubricants-lifetime-by-using-porous-materials

\section{INTECH}

open science | open minds

\section{InTech Europe}

University Campus STeP Ri

Slavka Krautzeka 83/A

51000 Rijeka, Croatia

Phone: +385 (51) 770447

Fax: +385 (51) 686166

www.intechopen.com

\section{InTech China}

Unit 405, Office Block, Hotel Equatorial Shanghai

No.65, Yan An Road (West), Shanghai, 200040, China

中国上海市延安西路65号上海国际贵都大饭店办公楼 405 单元

Phone: +86-21-62489820

Fax: +86-21-62489821 
(C) 2011 The Author(s). Licensee IntechOpen. This chapter is distributed under the terms of the Creative Commons Attribution-NonCommercialShareAlike-3.0 License, which permits use, distribution and reproduction for non-commercial purposes, provided the original is properly cited and derivative works building on this content are distributed under the same license. 